\title{
Giving IT a KICT
}

Successful Professional Development Models in Small, Semi Rural Schools

\author{
Martin James and Kay Rye
}

Paihia School, School Road, Paihia 0252, New Zealand

miha@voyager.co.nz

Keywords: primary education, catalyst for change, case studies, teacher education, transfer

\begin{abstract}
Interactive Education: An Information and Communication Technologies (ICT) Strategy for Schools was launched by the New Zealand Government in October 1998. The strategy is a concerted effort by the government at a national level to integrate ICT into teaching and learning programmes in primary and secondary schools. One strand of the strategy was the establishment of 23 ICT Lead Schools. This paper examines the work of Paihia School, one of the 23. The school underpinned its professional development programme with characteristics that research indicated promoted sustainable change in curriculum development when applied to school based professional development models
\end{abstract}

\section{INTRODUCTION}

Co-ordination of ICT use in New Zealand schools began to evolve in the early 1990's with the publication of the Consultel Report: "The use of telecommunication technologies for the enhancement of educational services". It warned against uncoordinated and unsupported implementation of new technologies into learning environments stressed the need for educators using the technology to be adequately trained and called for implementation to be well coordinated and funded.

Harris (2000) stated that a common theme amongst those interviewed by the authors of the Consultel Report was that technology in itself was not the answer. The technology was described as a tool, that had to be matched to 
educational methods in a way that 'augmented' or added value to learning to be successful.

It maintained that, "new technologies are teaching and learning tools. They do not substitute for teachers but technology developments provide an additional means by which learning can take place."

This study was primarily concerned with open learning and distance education, but its findings apply equally to all educational areas. While there were a range of initiatives involving ICT in the mid-1990's involving both business and the Ministry of Education it wasn't until 1998 that much of the work came together under a new strategy.

Interactive Education: An Information and Communication Technologies (ICT) Strategy for Schools was launched by the New Zealand Government in October 1998 (M.O.E. 1998). It was supported with a budget of $\$ 14.5$ million over three years. The strategy is a concerted effort by the government at a national level to integrate ICT into teaching and learning programmes in primary and secondary schools. One strand of the strategy was the establishment of 23 ICT Lead Schools, who work with approximately 300 cluster schools developing professional development models and supporting them in the integration of ICT into their schools over a three-year period. Paihia School is one of the 23 Lead Schools working with sixteen schools in the Far North region of New Zealand, they have developed a professional development model that effectively supports small, rural, semi isolated schools. This paper explores the foundations the model is built on, how it is being implemented and what impact the model is having on three of the schools involved. It indicates that there are common characteristics that exist in schools adopting ICT integration, where there was previously little or no expertise in this area.

\section{SETTING}

The Far North District, New Zealand

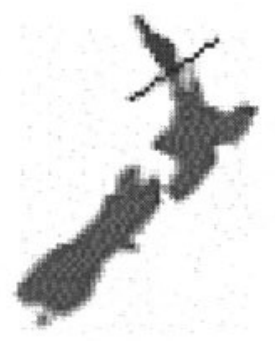




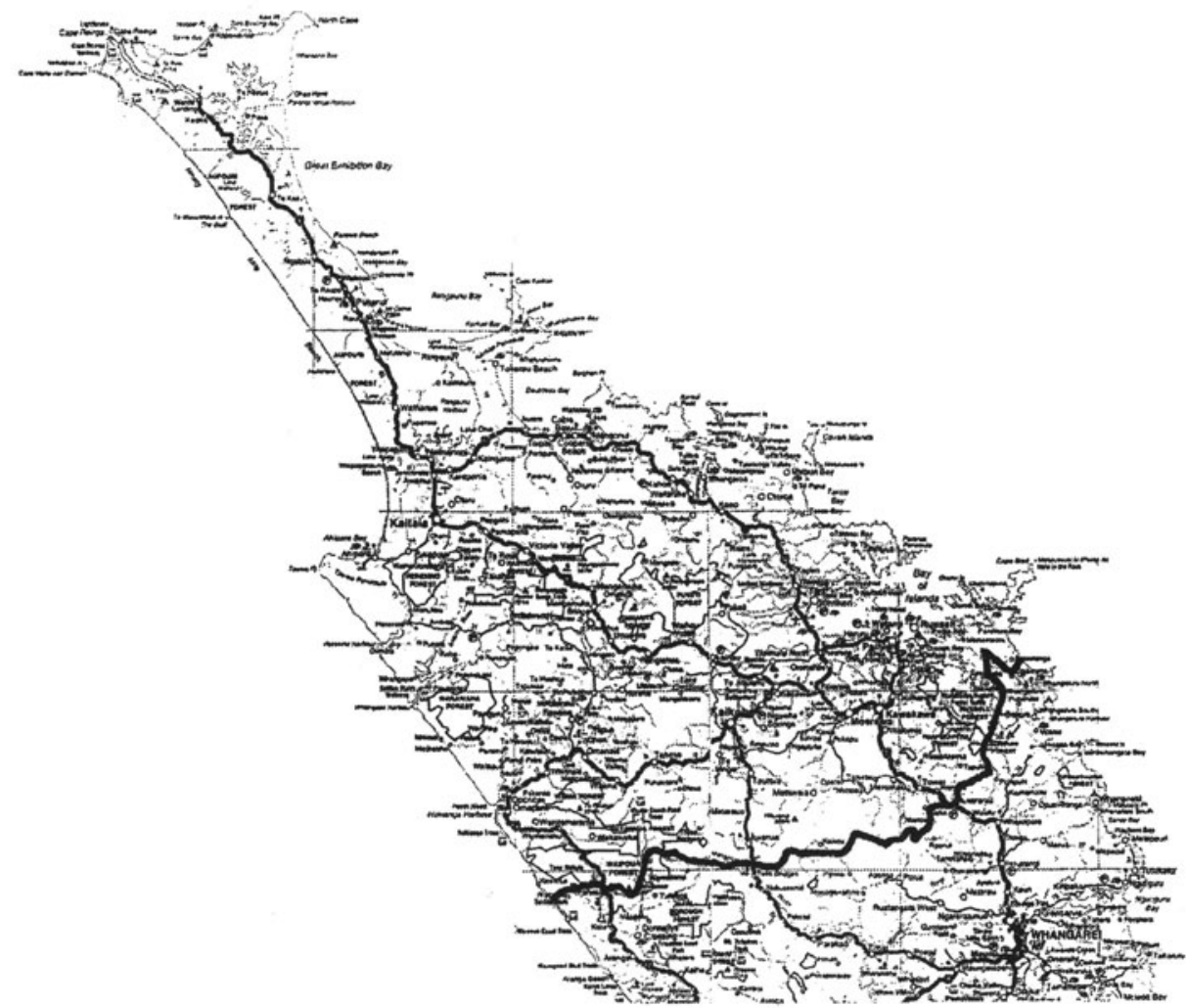

To understand the application of this professional development model and how the applied theory is put into practice one must first understand the social context of the schools in which the model is being applied. An Education Review Office (ERO 1998) report on Schooling in the Far North stated that, "A high proportion of students in the Far North can be classified as at risk as a result of their family and social circumstances". This statement was determined by OECD (1995). Family and social factors, which predict at risk status are:

- A background of poverty

- Ethnic minority status

- Fatures of family arrangements, such as single parent status

- Community factors such as poor housing

- Poor knowledge of the language of instruction.

The Far North population has a number of features which distinguish it from the rest of New Zealand. 
- There is a significantly higher Mäori population. Almost half of the Far North population (45.5 percent) identify as Mäori, compared with 15.1 percent in the whole of New Zealand.

- There is a greater proportion of older people and children. Compared to the New Zealand population as a whole, there are more young people aged 15 to 29 , more children aged 0 to 15 and more older people aged 50 to 69 .

- There is a lower level of educational attainment. In the Far North 43.8 percent of people aged over 15 have no formal qualifications, compared with 34.8 percent in the whole of New Zealand.

- There are more single parent families. One parent with child(ren) comprises 22.3 percent of families compared with 17.7 percent for New Zealand as a whole.

- There is a higher rate of unemployment. The unemployment rate is 12.9 percent compared with 7.7 percent in New Zealand.

- Income levels are lower. In the Far North 71.9 percent of people aged over 15 have an annual income of $\$ 20,000$ or less and 3.8 percent have an annual income of over $\$ 50,000$. The comparable figures for New Zealand as a whole are 58.6 percent and 7.3 percent. 31.1 percent of the Far North population aged over 15 receive a government benefit compared with 19.6 percent for New Zealand as a whole.

The Paihia School Cluster is made up of: 1 College (Years 9-13), 1 Area School (Years 1-13), 1 Intermediate (Years 7-8), 2 Kura Kaupapa Maori (Years 1-8 schools with instruction in Maori), and 12 Primary Schools (Years 1-8). These schools are spread throughout the Northland region across a longitudinal distance of $200 \mathrm{kms}$ and with a travelling time of two and a half-hours between the furthermost schools. All schools have:

- phone lines which allowed modem connections between 9600 and 28800 bps depending upon line quality

- electrical power supply of varying quality

- some form of computer technology varying in age from new to five years old.

\section{THE MODEL}

Underwood (1996) reported that the World Conference on Computers and Education Working Group concluded that there was a Cycle of Ignorance that had been created in the use of ICT, due largely to the rapidity of the IT innovation cycle, resulting in ineffective training and support in the use of IT for teachers. A strategy to break the cycle of ignorance consists of:

- Providing effective role models of good practice 
- Personal IT skills are a prerequisite to pedagogic change

- The process of self development needs to be repeated with our students

- Identifying factors that support effective transfer into the classroom is essential.

Our professional development programme is built upon these recommendations. At the heart of our model is the belief that in order to effectively integrate ICT into teaching and learning an examination of the teaching paradigms that exist within schools is necessary. The term 'authentic pedagogy' is used to describe the teaching and learning conditions we want schools to create. Our model provides teachers and principals in participating schools with opportunities to develop effective use and integration of ICT into their schools through:

- Exposing teachers and principals to models of best practice

- Supporting the development of their personal ICT skills

- Empowering students to develop innovative use of ICT

- Creating characteristics of successful change models in our cluster schools

Readings we explored on School Based Professional Development Models included the ACCO Model of Change, Robertson (1991) and subsequent evaluations by Hall, Casey and Robertson (1995). These, along with other evaluations of schools-based projects by Ramsey et al. (1990), Stringfield et al. (1991) and Poskitt (1992) indicated that, "in spite of numerous findings of international literature in this area, once a sound pattern of curriculum development is set in place, it is likely to be sustained providing that certain conditions are in existence". These conditions included:

- Teachers being involved in setting priorities for change with the time frame for change of sufficient duration

- School-wide change requires targeting whole staff development but also identifies key individuals to co-ordinate improvement

- Teachers must 'own' the change process by, becoming familiar with research that relates to effective practice, assessing current practices and setting performance goals

- An outside agent or facilitator is crucial in identifying needs, developing strategies and plans, as well as setting deadlines

- Ensuring that leadership develops a clear sense of direction and vision, which is agreed to by teachers

- Involving school communities in the development. 


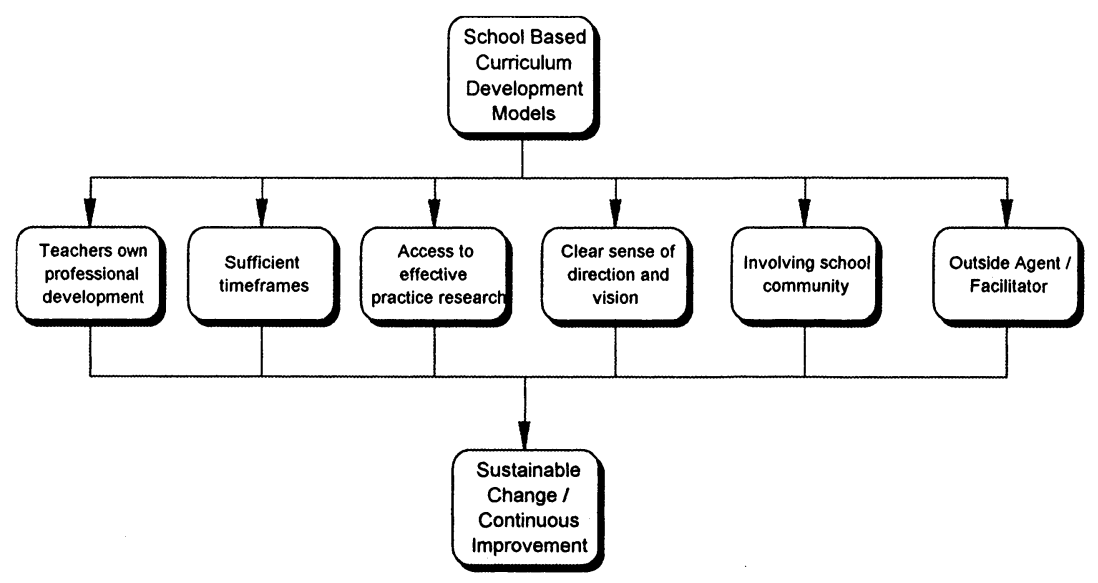

Figure 1. Conditions required for sustainable change

The model we developed encapsulates all these characteristics in some shape or form. The model has a two-strand approach. One strand targets principals and Boards of Trustees. The focus is to support them in developing appropriate policies and sustainable development plans for ICT in their schools, that look at infrastructure, teacher capability and application. This involves working directly with principals and board members in their schools. The second strand provides direct support to teachers in the classroom through the establishment of Key Information and Communication Teachers (KICTs) in all participating schools. The role of the KICT is to be actively involved in professional development focusing on:

- Personal ICT Skills

- ICT application in teaching and learning

- Learning Theory

- Developing PD Programmes for other staff members.

The goal is to create autonomy for schools in relation to ICT professional development and the development of an authentic pedagogy that effectively integrates ICT into teaching and learning programmes.

This is achieved through the creation of a sustainable resource in the KICT, who can support the schools professional needs. As the school evolves in developing its infrastructure and programmes it looks to its' KICT for direction and support in applying ICT to teaching and learning programmes.

Substantial research, based on the work of Fullan (1991), has shown that a change in pedagogical practice not only depends upon the willingness of the 
individual teacher but on policies and practices of the institution as a whole and of the culture within the institution. This research supports our two strand approach. One must also understand that the majority of New Zealand schools, because of their size, (average school size is less than 200 pupils) have teaching principals. Principals who are actively involved in teaching allow the two strands to entwine more readily, as small school principals maintain their role as curriculum leader, as opposed to some of the larger schools where the principals' administrative demands often mean curriculum leadership is delegated.

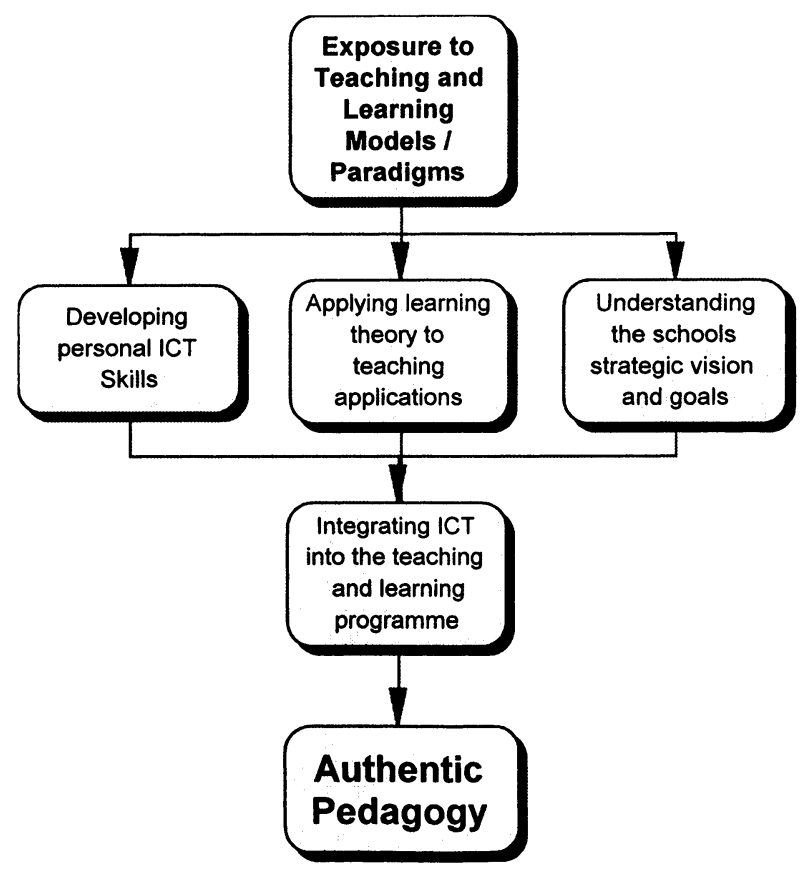

Figure 2. Conditions for creating authentic pedagogy

\section{CASE STUDIES}

The model we proposed for all schools is developmental in nature. The first step is working with schools in developing Key ICT teachers while at the same time working with principals developing strategic documentation. Each school is at a different place along the development continuum, 
depending upon previous professional development experiences. Some schools have pockets of ICT innovation occurring. None of the 16 schools at the beginning of the contract had school-wide ICT PD programmes. Although a number of the schools included ICT equipment replacement as part of their strategic plans, there was no evidence of ICT professional development programmes with an ICT focus.

\subsection{School 1}

A bi-lingual full primary sited in a small town. It is the largest of the cluster primary schools with a teaching staff of 16 . In response to the large number of Maori pupils enrolled, the school operates a parallel stream of four classrooms for Year 1-8 students, in which the language of instruction is Te Reo Maori. Teachers, aides and students must speak Maori at all times, although the students write in English and use English texts.

The Principal, is an active user and supportive in the provision of ICT equipment. However there is little technical expertise within the staff and no apparent planned ICT strategy.

\section{Elements identified that support ICT development}

- Stable staff

- Principal active user

- Key teachers were in positions where they would be able to effect change.

The identified key teachers were the deputy principal and the most competent ICT user in the immersion classes. Both carried a full teaching load as well as administrative responsibilities. In order for them to engage with enthusiasm, it was essential that the professional development enhanced their current classroom practice rather than created another job. This requirement has determined the direction of ICT integration throughout the school. ICT must be used in authentic contexts and in the most appropriate way. There will be very few contrived student uses of ICT in this school. The immersion teacher had a further particular need - how to effectively use ICT to promoting exemplary models of Te Reo Maori.

During 1999, both teachers received 8 in-school visits. Four visits were to teach skills needed to pass on to their students. The balance of visits were professional discussions - the rationale of ICT use, management and organisation issues and programme planning.

In the second year, 2000, the two KICT's and the external facilitator delivered a similar professional development programme after-school to 6 more teachers. The teachers were then expected to pass their skills on to their students. In the third year, the 6 teachers will work with team members 
to pass on their skills while the KICT's will receive further individual skills training to start the cycle again.

\subsection{School 2}

A 3 teacher full primary school sited 8 kilometres from their nearest shop and 17 kilometres from their nearest high school. School 2 is typical of many New Zealand rural primary schools. Virtually all their students are bussed to school from the surrounding farms and the staff live nearby, but not necessarily within the school community.

Elements identified that support ICT development

- Stable staff who all planned ICT use for their students

- All three staff were users of ICT

- Key teacher was positive towards change

- High computer/student ratio - (1:5).

Whilst the principal and school secretary worked within the network of learning principals to develop ICT use in their administrative processes, the KICT worked with the external facilitator.

In the first year, 1999, the immediate need was to develop some management strategy which would allow her Year 1 to 3 students to independently access the word processor to complete language tasks. The KICT learned how to write macros that delivered the required document to the desktop setout with the desired font, style, and student cues.

This successful strategy allowed the KICT and facilitator to explore other ICT tools in the school. By the end of the year, her students had all used the fax, the speakerphone and digital camera successfully and understood how each tool empowered them. In the second year, the staff identified their individual ICT needs, which were then addressed by the KICT and external facilitator in a series of after school workshops. Two final staff meetings with the facilitator helped the staff clarify their school's ICT philosophy and rationale of use.

\subsection{School 3}

The school already had a teacher who was effectively integrating ICT into teaching programmes. The principal was already using effective professional development models for change in other curriculum areas. There were coordinated efforts to improve access to ICT for all students. The principal also possessed strong personal ICT skills.

Elements identified that supported ICT development.

- Stable staff 
- Key teacher technically capable and innovative user and supporter of other staff

- Principal supportive and active user

- Effective professional development model already existed.

As the school had an infrastructure that was already place, the school was already providing staff training sessions both at syndicate and whole school level on using computers. The entry point for the outside facilitators was further along the continuum than at other contract schools because of this. The school was also able to manage minor technical issues. In the first year facilitators worked with the principal on developing an ICT strategic plan as well as providing personal ICT skills. The principal was prepared to apply these new skills and was seen by staff as an active user of ICT in teaching programmes. The Key ICT teacher was supported in the classroom in developing student mentors who could work alongside students from other classrooms. The second year saw the school move to a whole school development model where the key teacher was released to provide professional support for other teaching staff. The programme evolved to where staff were setting performance goals in the use of ICT. They were supported in the classroom by the key teacher. The model worked where by time was spent on both personal IT skills and the application of these skills into teaching programmes. The contract was able to support the school in funding some of the release time necessary for the key teacher to work in this way. The external facilitator worked with support staff rather than teachers on personal ICT skill development, as the internal release time was unable to be extended to pick up these staff members. While in most instances, the need for an external change agent is required through the change process, the school in this case was able to pick up much of this person's role. In 2001 the key teacher will be released to apply this model of professional development in other small Northland schools.

\section{SUMMARY}

Creating a network of learners suggests some form of link. The link that binds each network, each learning community or each school in this instance is ICT. Creating a consistent group of characteristics that are proven to support school based curriculum development initiatives has been critical to the success of the programme to date. The developmental nature of the programme and the varying degrees in which individual schools enter this continuum of development has allowed us to predict future directions for many of the schools. In schools where these characteristics are strong, one can see a growing autonomy, schools becoming less dependent upon outside 
agents and taking greater responsibility for ICT integration. Once organisations begin to develop this autonomy, they then become more aware of it interdependence on other learning networks, other links to support their own understanding and use of ICT in teaching and learning. Inter-school / organisational interactions at regional, national and international levels increase as the level of autonomy increases. The establishment of a national education portal (www.tki.org.nz) supports such interactions in New Zealand. The challenge for schools is to ensure that, as they adapt to include ICT into their teaching and learning programmes, more and more time needs to be spent examining the teaching paradigms that ICT is built on. While this model to date is producing more innovative use of ICT in authentic learning contexts, we must continue to examine the authenticity of the activities we expose our learners to. They must be imbedded in sound learning theory with technology that allows learners to do things in new ways, or ways in which traditional learning tools do not allow. Creating a critical mass of teachers who operate in this form of paradigm will ensure effective models of ICT integration are sustainable and on going.

\section{REFERENCES}

ERO (1998) Schooling in the Far North.

[http://www.ero.govt.nz/Publications/eers1998/far_north/farnorth1.htm].

Fullan, M. (1991) The New Meaning of Educational Change. Teachers College Press, New York.

Hall, A., Caesy, G. and Robertson, J. (1995) A resounding ACCO. Educational Leadership Centre, University of Waikato, Hamilton, New Zealand.

Harris, D. (2000) Information and Communication Technology in the New Zealand Educational Context. NZCER. [http://www.minedu.govt.nz/Schools/ITinSchools/].

M.O.E (1998) Interactive Education: An Information and Communication Technologies (ICT) Strategy for Schools. Ministry of Education, Wellington.

Poskitt, J. M. (1992) Report on the ACCO Teacher Development Contracts. Educational Research and Development Centre, Massey University, Palmerston North.

Robertson, J. (1991) ACCO: Achieving Charter Curriculum Objectives. Final Report TD 90/1, The University of Waikato, Hamilton, New Zealand.

Stringfield, S., Billing, S. and Davis, A. (1991) Implementing a Research-based Model of Chapter 1 Programme Improvement. Phi Delta Kappan, April, pp. 600-606.

Underwood, J. D. M (1996) Breaking the Cycle of Ignorance: Information Technology and the Professional Development of Teachers. Chapman and Hall, London. 


\section{BIOGRAPHY}

Martin James and Kay Rye have worked on a range of collaborative ICT related projects over the last eight years in their varying roles as teachers, principals and advisers. Much of this work has been in small, rural primary schools. Kay has been involved with the Te Kite Ipurangi Reference Group while Martin has been part of the reference group developing the new government ICT strategy. 